\title{
Cooling Aluminium Coils by Outdoor Air
}

Dieter Sedlacek and Berenika Hausnerova

Tomas Bata University in Zlín, Zlín, Faculty of Technology, Czech Republic. dsedlacek@utb.cz

\begin{abstract}
Aluminium extraction and production is energy intensive and have a relatively large environmental impact. One of the steps in the production of sheet aluminium is the cooling of the rolled metal after the hot mill. This study introduces an option to replace the active cooling by an environmental friendly method and eliminate the otherwise necessary logistic step of relocating the coils after cooling. This was done by developing a thermal model of the coils, calculating, based on the model, the required airflow and verifying it with test series. The experimental setup is in a high-bay storage facility belonging to a aluminium production line. The results of the test series show the differences between simulations and real life settings.
\end{abstract}

Keywords: Energy efficiency, Cooling coils, High-bay storage, Outdoor air, Energy savings

\section{Introduction}

Ecological and energy problems are increasing all over the world. The green movement is forcing the industry to make their products more sustainable and to think more and more about their ecological footprint to minimize the impact of the ongoing climate change. Aluminium is a material that is indispensable or irreplaceable in many areas of application. Be it in the manufacture of light products such as cars, packaging, construction or applications in the electronics industry. Thermal conductivity, low weight and durability are the main properties that make it so valuable for the use in many industries.

However, the extraction of aluminium is very energy intensive. Alumina processed from bauxite is the base material for the aluminium extraction, which is done by electrolysis. Both steps in the extraction consume large amounts of energy [1].

One of the further steps in the fabrication line to the finished product made of aluminium is the rolling of the aluminium blocks to sheet metal. Coming out of the hot mill, the sheet metal is wound up to a coil. Coils are the intermediate product for the production of aluminium sheet, strip and plate. Aluminium sheet, strip and plate are defined by national and international standards like DIN EN 485.

After coming from the hot mill, the coils have a temperature of approx. $350^{\circ} \mathrm{C}$. The rolls are then cooled down to about $50^{\circ} \mathrm{C}$ for the next steps in production. Active cooling systems bring the rolled sheet aluminium down to the desired temperature. Then the coils are stored in a warehouse that functions as a buffer that optimizes the flow of material between the production steps. The remaining time of the aluminium drums in the warehouse is approx. 60 hours. The cooling is done before the coils go into storage to keep the necessary storing places at a minimum. In modern aluminium production, the buffer comes as a highly automated high bay storage facility.

Previous studies address the rolling of aluminium to sheet metal and in particular the thermal behaviour and the physical properties of the metal [2-8].

Other previous articles deal with the thermal behaviour of aluminium and other metals concerning products in electronics like heat exchangers and cooling coils or in solar thermal applications [9-18]. There are also textbooks and research articles that focus on sheet metal and their thermal behaviour and the properties of heat transmission [19-22]. However, these examples are mainly based on the effects in electronic applications, as mentioned before. No study or textbook covers the thermal behaviour of rolled aluminium as in transportation coils.

The cooling process is a step in the production line that plays a minor role in the energy consumption compared to the whole aluminium industry. Nevertheless, the cooling is highly power intensive and not very efficient. In addition, it is an inescapable logistic step to the production line.

To replace the active cooling by an environmental friendly method and eliminate the otherwise necessary logistic step of relocating the coils after cooling is the aim of this study.

Thus, this work introduces a method how to eliminate the relocation of the coils by leaving them in their designated storage place in the buffer and cooling the coils there on the spot by simply using outdoor air and still matching the given time limit.

\section{Methods}

In order to cool the coils with outside air only and leave them in storage at their place, a thermal model of the coils had to be created first. The necessary air volumes were then determined according to this model. Then coils from the actual production were measured to verify the calculations and the model with its specific approximations.

For this study, two sets of aluminium coils were used. One set consisted of smaller coils and the other of larger ones. The coils were used from a real production series and therefore differed from the given characteristics and dimensions of the model. The maximum typical coil data were first used to calculate the model. The actual data of the test coils were only known shortly before the measurements were carried out. Therefore, the air volume of the duct and fan wase designed for the maximum requirements and were adjusted accordingly for the tests.

Coils typically have certain maximum dimensions. 
They have a length $\mathrm{L}$, an outer diameter $\mathrm{D}_{\mathrm{a}}$, an inner diameter $\mathrm{D}_{\mathrm{i}}$ and a number of layers that depend on the thickness of the aluminium sheets.

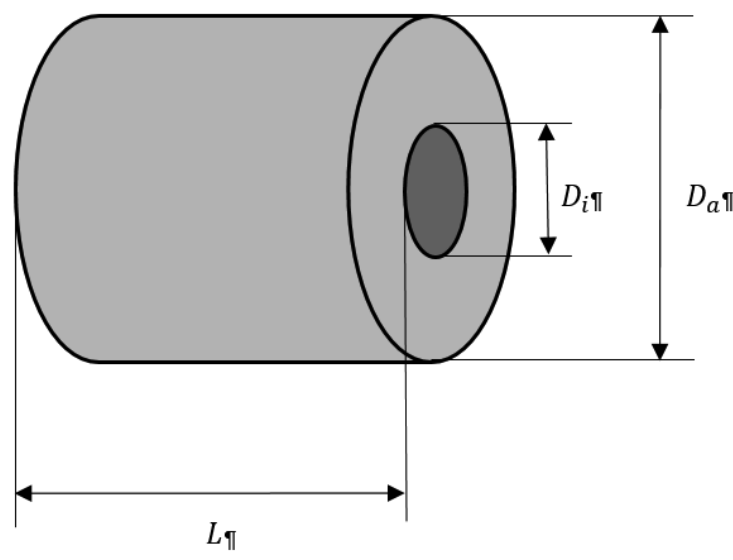

Fig. 1 Dimensions of aluminium coil

The calculation of the energy content of a coil is defined by the following equation that can be found in most textbooks on the basics of thermodynamic [23]:

$$
Q=m \cdot c_{p} \cdot d T
$$

where $Q$ is the energy content of the object, $\mathrm{c}_{\mathrm{p}}$ is the specific heat capacity of the material, $m$ stands for the mass and $d T$ is the temperature difference between the object und the ambient conditions. $Q=m \cdot c_{p} \cdot d T$

\subsection{Mathematical Model of Aluminium Coils}

To create the thermal model of the coil, its surfaces had to be determined. This is important for the heat transfer during the cooling period. Then the energy or heat content of the coil was determined. Together with the different types of heat transfer, the cooling progression and the required airflow could be calculated.

There are two ways of heat transfer between the coil and the surrounding environment. One is convection; the other is radiation. With the given dimensions of the coil, as shown in Fig. 1, the surface of the coil for heat transfer is made up of various partial surfaces. The jacket surface is the surface of a cylinder. The same applies to the inner surface of the coil axis. For the jacket surface $A_{j}$ the equation is a simple geometric one.

$$
A_{j}=L \cdot \pi \cdot D_{a}
$$

where $L$ stands for the length of the cylinder. For the inner surface $A_{i}$ applies the same equation.

$$
A_{i}=L \cdot \pi \cdot D_{i}
$$

For the front face or lateral face of the cylinder $A_{l}$, the surface of the inner hollow cylinder must be subtracted from the entire circular surface.

$$
A_{l}=\pi \cdot\left(\left(\frac{D_{a}}{2}\right)^{2}-\left(\frac{D_{i}}{2}\right)^{2}\right)
$$

The total surface for radiation $A_{\Sigma r}$ is the addition of all the partial surfaces.

$$
A_{\Sigma r}=A_{j}+A_{i}+2 A_{l}
$$

The total surface $A_{\Sigma c}$ that can be used for convection specifically in the given case is an addition of the jacket surface, the inner surface but only one lateral surface. The reason for this is that no duct routing can be placed on the side on which the coil is stored and removed again.

$$
A_{\Sigma c}=A_{j}+A_{i}+A_{l}
$$

The energy or heat content $\mathrm{Q}$ of the aluminium coil can be expressed as

$$
Q=m \cdot c_{A l} \cdot \Delta \delta
$$

where the specific heat capacity of aluminium is $c_{A l}$, $m$ is the mass of the coil and $\Delta \delta$ is the temperature difference between the surface of the coil and the ambient air.

The heat transfer by convection $\dot{Q}_{c}$ is defined by [24]

$$
\dot{Q}_{c}=\alpha \cdot A_{\Sigma c} \cdot \Delta \delta
$$

where $\alpha$ is the heat transfer coefficient, $A_{\Sigma c}$ is the effective surface for the heat transfer by convection (Eq.(6)) and $\Delta \delta$ is the temperature difference.

The other type of heat transfer, the transfer by radiation $\dot{Q}_{r}$ is formulated by $[24,25]$

$$
\dot{Q}_{r}=\varepsilon \cdot \sigma \cdot A_{\Sigma r} \cdot\left(T_{A l}^{4}-T_{U}^{4}\right)
$$

This is the so called Stephan-Boltzman-law, where $\sigma$ $=5.67 \cdot 10^{-8}\left[\mathrm{~W} /\left(\mathrm{m}^{2} \mathrm{~K}^{4}\right)\right]$ is the Stephan-Boltzman-constant, $T_{A l}$ is the absolute coil temperature in Kelvin, $T_{U}$ is the absolute ambient temperature also in Kelvin, $A_{\Sigma r}$ stands for the surface of the coil as mentioned in Eq. (5 )and $\varepsilon$ is the emissivity of the surface of aluminum (aluminium-mill-finished [25]).

With the above listed equations, the model of the coil is complete. The temperature progression of the coil during the cooling process follows an exponential function of the Euler number [23]. The resulting heat flow during the progression can be expressed as

$$
\dot{Q}_{(t)}=\dot{Q}_{(t=0)} \cdot e^{\frac{-t}{\tau}}
$$

where $Q_{(t)}$ is the remaining heat content of the coil at any interval, $Q_{(t=0)}$ is the heat content at the start interval, which is the sum of $\dot{Q}_{r}$ and $\dot{Q}_{c}$, t is the time of the interval and $\tau$ is the resulting time based on the heat transfer during a given interval as in the following equation.

$$
\tau=\frac{Q_{(t)}}{\dot{Q}_{(t)}}
$$

Finally, the resulting airflow $Q_{\text {air }}$ is determined by

$$
Q_{\text {air }}=\frac{\dot{Q}_{(t)}}{c_{p} \cdot \rho \cdot\left(T_{c}-T_{a i r}\right)}
$$

where $T_{c}$ stands for the coil temperature, $T_{a i r}$ is the temperature of the airflow, $c_{p}$ is the isobaric specific heat capacity of air and $\rho$ stands for the air density. 


\subsection{Experimental setup}

In the experiments, there were two sets of coils co- ming directly from the hot mill used for the measurements. The current production orders dictated the size and dimensions of the coils. All had an inner diameter of 600 $\mathrm{mm}$.

Tab. 1 List of test coils

\begin{tabular}{lllll}
\hline Coil No. & L $[\mathrm{mm}]$ & Da $[\mathrm{mm}]$ & Weight $[\mathrm{kg}]$ & Sheet thickness $[\mathrm{mm}]$ \\
\hline Small coils & & & & \\
\hline $44 / 1$ & 1650 & 1900 & 12015 & 3 \\
$44 / 4$ & 1650 & 1940 & 11880 & 3 \\
$44 / 7$ & 1580 & 2060 & 12935 & 6 \\
$47 / 3$ & 1580 & 2070 & 13010 & 6 \\
$47 / 7$ & 1580 & 2080 & 13005 & 6 \\
\hline Large coils & & & & \\
\hline $42 / 1$ & 1940 & 2260 & 19480 & 3 \\
$51 / 5$ & 1940 & 2330 & 20935 & 3 \\
$52 / 1$ & 1940 & 2320 & 21060 & 3 \\
$52 / 7$ & 2040 & 2250 & 19795 & 3 \\
$54 / 7$ & 2040 & 2260 & 19805 & 3 \\
$56 / 5$ & 1940 & 2344 & 21100 & 3 \\
\hline
\end{tabular}

The control system placed the coils in a distributed pattern into the high bay storage for the setup of the series of measurements. The numbers corresponded to the location of the aluminium drums, e.g. coil 44/4 stood for column 44 and level 4 bin. The distribution was necessary to avoid the mutual influence of the hot drums and to exclude the impact of the airflow by the design of the air duct.

Fig. 2 shows part of the construction drawing of the experimental setup. The magenta part of the drawing is the air duct with its outlet grids that eject the airflow onto the coil surfaces. The red lines indicate the direction of the airflow. The gray lines outline the coil (front view) with its two support structures.

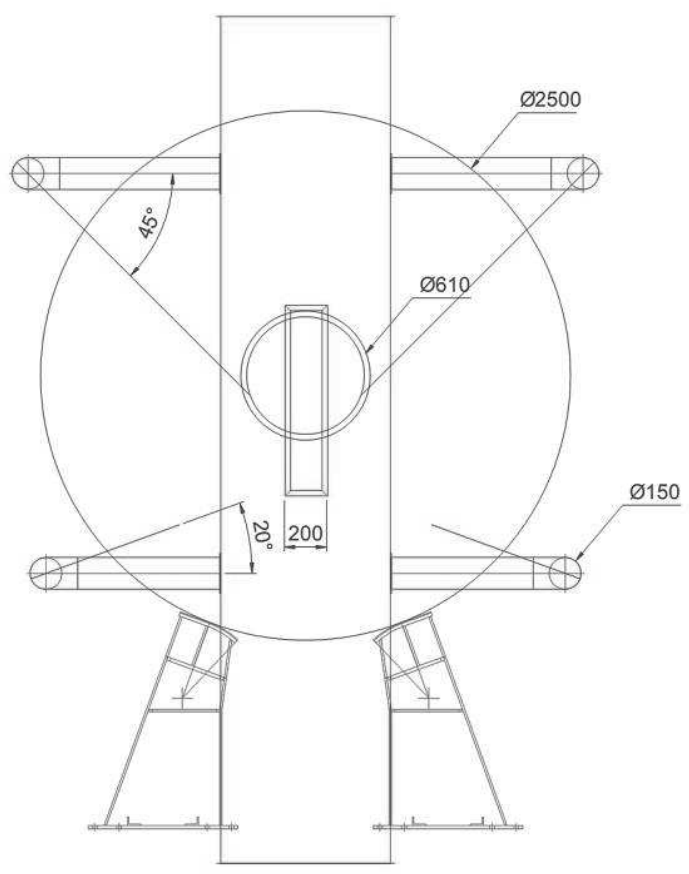

Fig. 2 Front view of experimental setup
The measured variables were the temperature of the front and shell surfaces in intervals, the temperature of the outside air and the time of the individual measurements. The availability of the storage and retrieval machines determined the measuring intervals. Specially trained staff operated the stacker cranes manually to reach the desired coil and take the measurements.

The TC 301 model from Dostmann electronic with surface sensor was used as the measuring device for the coil temperature. The control system of the storage facility logged the outdoor air temperature. The sensor was placed in the air duct close to the ventilator. The axial fan used for the setup was a R3G800-AQ03-XA model from ebm.

\section{Results}

Initial values and conditions for calculating the required airflow and temperature progression are listed in Tab. .

\section{Tab. 2 Initial Setup}

Temperature of incoming coils: $\quad 350^{\circ} \mathrm{C}$

Temperature of outgoing coils: $\quad 50^{\circ} \mathrm{C}$

Average outdoor air temperature: $\quad 25^{\circ} \mathrm{C}$

Average indoor air temperature $\quad 42^{\circ} \mathrm{C}$

Coil weight: $\quad 26 \mathrm{t}$

Coil outer diameter: $\quad 2500 \mathrm{~mm}$

Coil inner diameter: $\quad 610 \mathrm{~mm}$

Coil width $\quad 2400 \mathrm{~mm}$

Time limit 1 for cooling $\quad 45 \mathrm{~h}$ to $60^{\circ} \mathrm{C}$

Time limit 2 for cooling $\quad 50 \mathrm{~h}$ to $50^{\circ} \mathrm{C}$

With the initial setup data and Eq. (2) - (6) the surface for radiation computed to $A_{\Sigma r}=32.68 \mathrm{~m}^{2}$ and convection to $A_{\Sigma c}=28.07 \mathrm{~m}^{2}$.

With Eq. (7) the heat content of the aluminium coil was $Q=2,271 \mathrm{kWh}$. For calculating the heat transfer by 
convection (Eq. (8)) according to EN ISO 6946 the approximation for forced air was used which resulted with $\alpha \approx 20 \mathrm{~W} / \mathrm{m}^{2} \mathrm{~K}$ in $\dot{Q}_{c}=182.4 \mathrm{~kW}$. With Eq. (9) the radiation was calculated to $\dot{Q}_{r}=12.97 \mathrm{~kW}$ and the total heat transfer as the sum of $\dot{Q}_{c}$ and $\dot{Q}_{r}$ came to $\dot{Q}_{\Sigma}=195.37 \mathrm{~kW}$. As a safety margin for deviations of the real setup from the theoretical model, e.g. minimal air layers between the windings, $20 \%$ was applied. The heat transfer including the safety margin was therefore reduced to $\dot{Q}_{\Sigma \text { safe }}=162.83$ $\mathrm{kW}$.

These calculated values resulted with Eq. (10) in $\dot{Q}_{(t)}=151.57 \mathrm{~kW}$ for the heat transfer at the end of the first one-hour interval with a time constant $\tau=13.9 \mathrm{~h}$, as shown in Eq. (11). The resulting airflow with Eq. (12) computed to $Q_{\text {air }}=1,390.72 \mathrm{~m}^{3} / \mathrm{h}$.

The airflow simulation showed that in an open environment, like the one in the warehouse, not all air could be effective administred to the surface of the test object.

Based on these results, the air volume for the design of the fan and the air duct was doubled. The nominal air volume of the test arrangement was set to $2,800 \mathrm{~m}^{3} / \mathrm{h}$. This should also ensure a sufficient control range was available.

The measurements were taken in a real life scenario and not in a laboratory. Therefore, many possible deviations and influential factors could not be addressed in the computations. These influences result, for example, from the surrounding steel structure, the degree of contamination of the outdoor air, the tightness of the air ducts, etc.

\subsection{Results of simulation with initial setup}

Using the input conditions, the simulation of the temperature curve (Graph 1) showed that without additional measures a coil needs more than $100 \mathrm{~h}$ to cool down to the first target temperature at the given average outdoor temperature. For the second, additional $20 \mathrm{~h}$ are required. With the typical ambient temperature in a warehouse of $42{ }^{\circ} \mathrm{C}$, these time intervals stretch to over $130 \mathrm{~h}$ and 160 h.

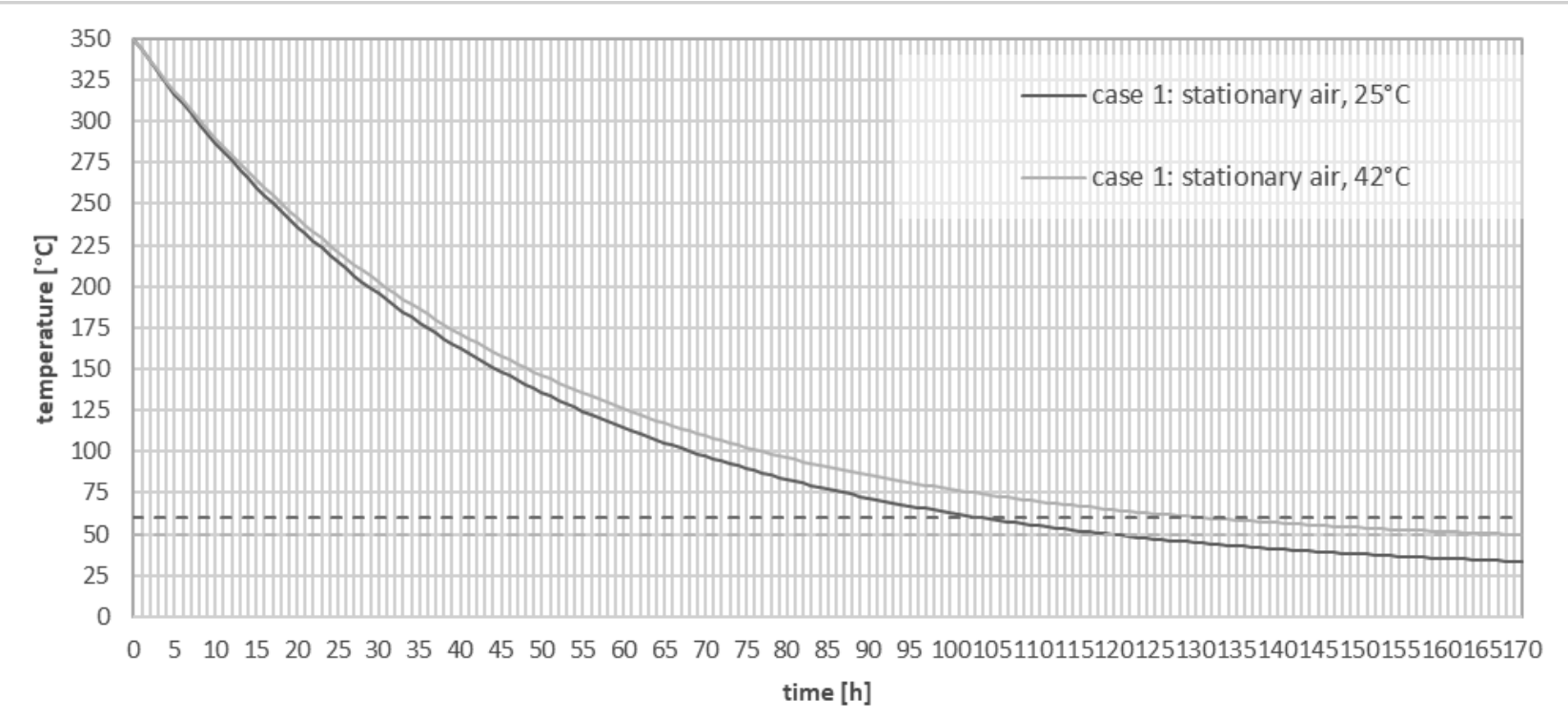

Graph 1 Cooling curve, no forced ventilation, ambient temperature $25^{\circ} \mathrm{C}$ and $42{ }^{\circ} \mathrm{C}$

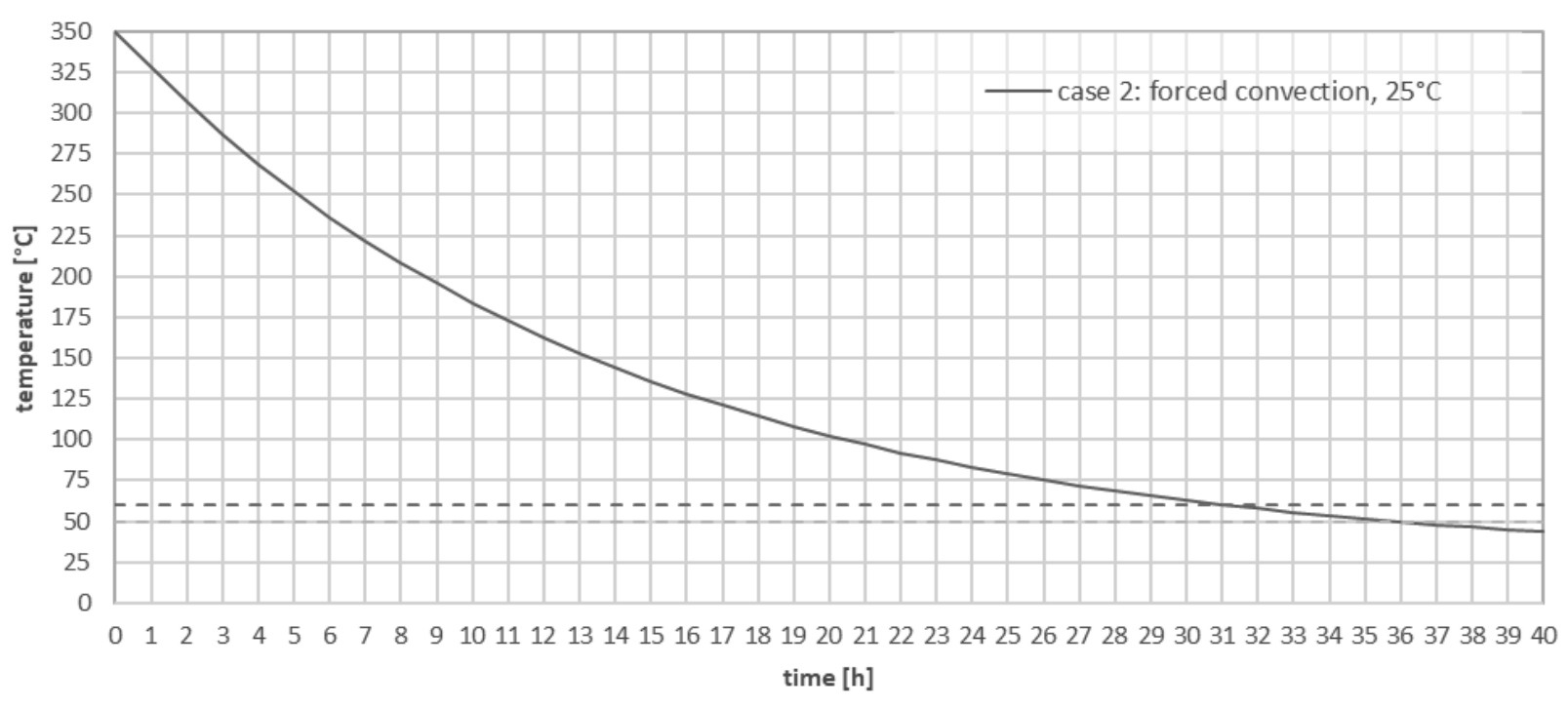

Graph 2 Cooling curve, forced convection, outdoor air $25^{\circ} \mathrm{C}$ 
The further simulation with the given conditions and the calculated air quantities resulted in a cooling of the metal drum up to the first limit within $30 \mathrm{~h}$ and up to the second below $35 \mathrm{~h}$, as shown in Graph 2.

\subsection{Comparison of simulation with actual results}

For the comparison of the actual results with the simulations, two typical aluminium coils were chosen. One from the smaller coils (No. 44/7,Graph 3) and the other (No. 51/5, Graph 4) from the large set of metal drums. The measurements showed that the simulation best approached the real situation when the value of the approximation in Eq. (8) was set to $\alpha \approx 16 \mathrm{~W} / \mathrm{m}^{2} \mathrm{~K}$. The average outdoor temperature was $28^{\circ} \mathrm{C}$ for $44 / 7$ and $30^{\circ} \mathrm{C}$ for coil no. $51 / 5$.
The results of the measurements, as shown in Tab. 3 , Tab. 4, Graph 3 and Graph 4, were close to the simulation. However, the following points must be observed. Due to the supply air grids, which were directed in a fixed manner towards the largest possible coil (Initial setup, Tab. 2), a large part of the airflow passed the test objects with a limited effect in the open environment of the warehouse. This affected the small coil in particular because it had the largest geometric differences compared to the metal drum in the initial data set. It turned out that the difference in size and the resulting reduction in effective air volume was compensated by the lower energy content. The coil was therefore cooled down within the required time and temperature (Tab. 3, Graph 3).

Tab. 3 Data of coil 44/7

\begin{tabular}{lllll}
\hline Time $[\mathrm{h}]$ & Measured Temperature $\left[{ }^{\circ} \mathrm{C}\right]$ & Calculated Temperature $\left[{ }^{\circ} \mathrm{C}\right]$ & Difference $\left[{ }^{\circ} \mathrm{C}\right]$ & Relative Difference. \\
\hline 0 & 320 & 320 & 0 & $0 \%$ \\
1 & 284 & 300 & -16 & $-5 \%$ \\
17 & 120 & 121 & -1 & $-1 \%$ \\
22 & 94 & 94 & 0 & $0 \%$ \\
25 & 83 & 82 & 1 & $1 \%$ \\
41 & 47 & 46 & 1 & $2 \%$ \\
\hline
\end{tabular}

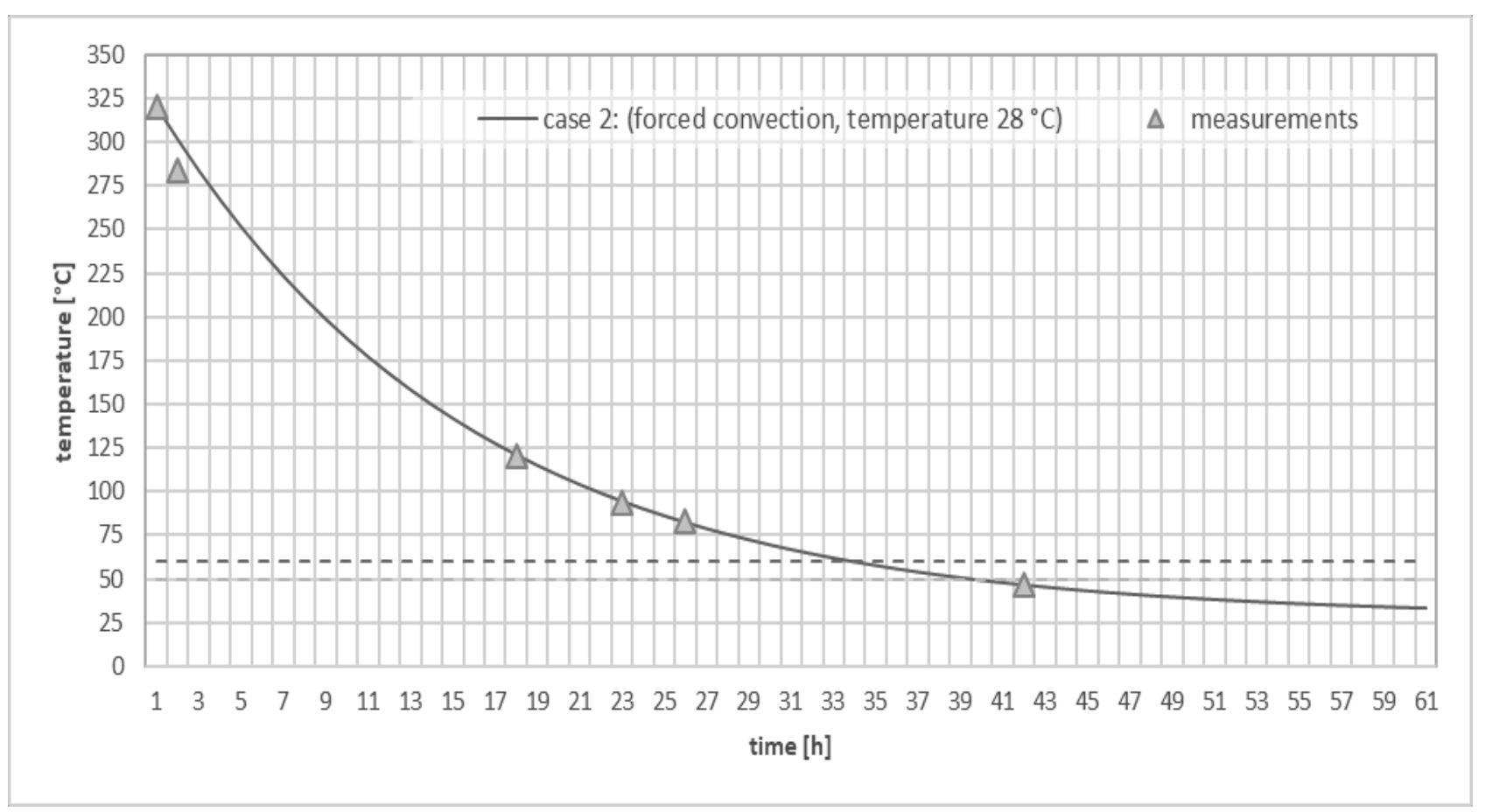

Graph 3 Cooling curve of coil 44/7

Tab. 4 Data of coil 51/5

\begin{tabular}{lllll}
\hline Time $[\mathrm{h}]$ & Measured Temperature $\left[{ }^{\circ} \mathrm{C}\right]$ & Calculated Temperature $\left[{ }^{\circ} \mathrm{C}\right]$ & Difference $\left[{ }^{\circ} \mathrm{C}\right]$ & Relative Difference. \\
\hline 0 & 260 & 260 & 0 & $0 \%$ \\
1 & 248 & 248 & 0 & $0 \%$ \\
16 & 119 & 124 & -5 & $-4 \%$ \\
18 & 105 & 114 & -9 & $-8 \%$ \\
22 & 94 & 97 & -3 & $-3 \%$ \\
24 & 86 & 90 & -4 & $-4 \%$ \\
42 & 48 & 51 & -3 & $-6 \%$ \\
46 & 44 & 46 & -2 & $-4 \%$ \\
\hline
\end{tabular}




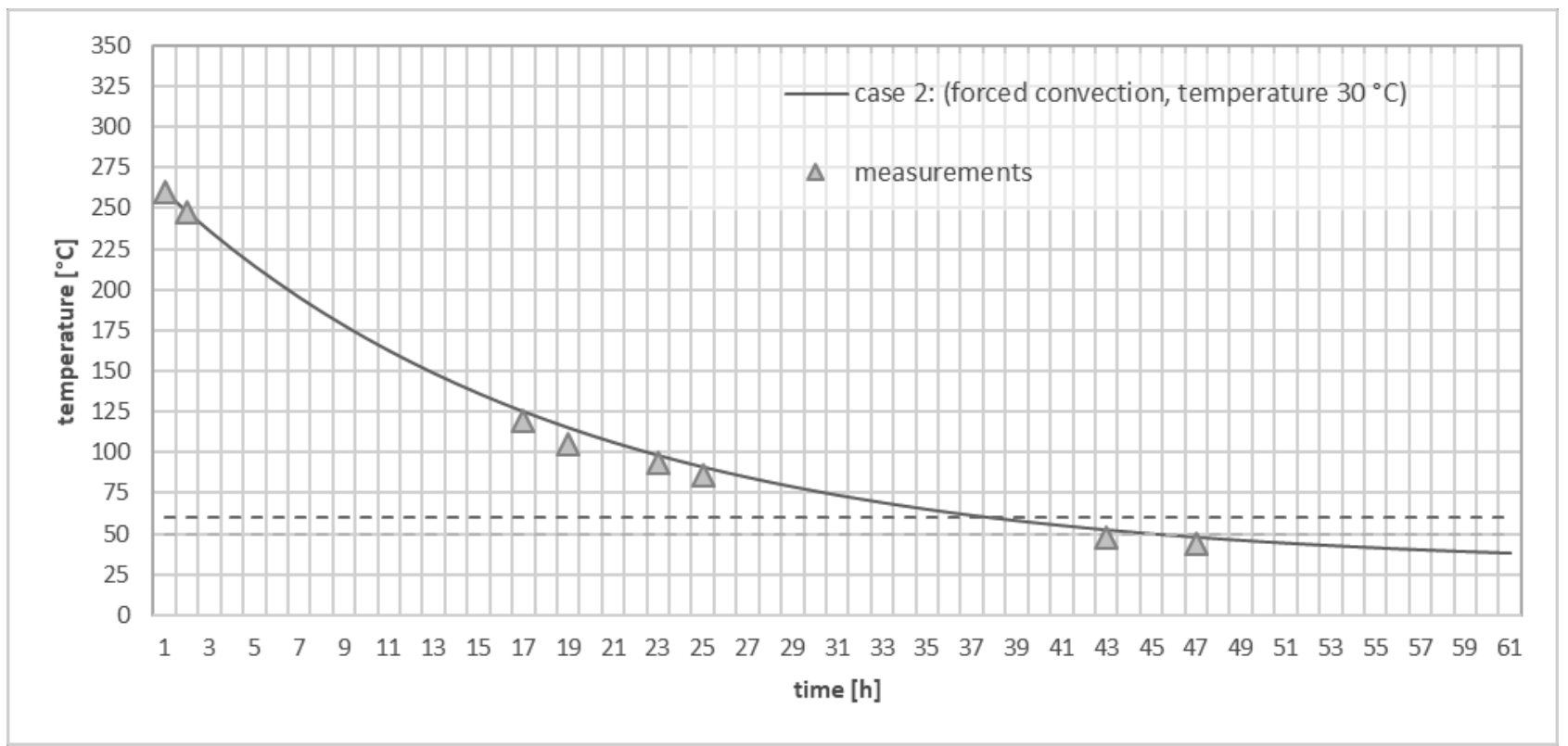

Graph 4 Cooling curve of coil 51/5

The same happened to $51 / 5$ as shown in Tab. 4 and Graph 4.

For both drums, the corresponding fan was running at the nominal load with $2,800 \mathrm{~m}^{3} / \mathrm{h}$ and an average air velocity of $4 \mathrm{~m} / \mathrm{s}$ at the grids. The number of layers, i.e. the thickness of the aluminium sheets showed no or very little influence on the thermal behaviour of the test objects. The thermal connection between the layers was so good that the drums behaved as if they were made of solid metal.

\subsection{Airflow and system efficiency}

To visualize the airflow, several smoke grenades were launched in the mixing chamber of the air duct right before the fan. The smoke was blown in the supply duct and made the supply air visible streaming around one of the coils. This experiment showed that the upper grids and the grid in the back were the most efficient to bring the airflow to the test object. It also made it visible that not the entire jacket surface was evenly supplied with the airflow.

The power consumption of the ventilation system came the motor of the fan. It took between $33 \mathrm{~h}$ (coil no. 44/7) and $36 \mathrm{~h}$ (coil no. 51/5) to achieve the first temperature limit of $60^{\circ} \mathrm{C}$. During this time, the fan used $500 \mathrm{~W}$ electrical power. This equals a power consumption of $18 \mathrm{kWh}$. In comparison, a chiller $(\mathrm{EER}=4)$ generating the same cooling capacity consumes approx. $290 \mathrm{kWh}$. This is over 16 times more than in the experimental setup.

\section{Discussion}

As no study before has addressed the cooling and storage part of the aluminium production cycle, it is necessary to look at all production steps to optimize and eliminate or reduce the ecological footprint. However, the resulting application must also be economically feasible. This was the aim of our study.

This study indicates that there is a chance to reduce a significant amount of power consumption and therefore $\mathrm{CO}_{2}$ output in the cooling of aluminium coils when put into storage after coming from the hot mill. This should be achieved by the use of outdoor air only. However, the rolled aluminium cannot just be put outside in an open area because the coils must not get wet. Otherwise, water would compromise the coil's surface.

The results show that just waiting for the metal drums to cool down on their own by placing them in a space with outdoor temperature takes over $100 \mathrm{~h}$ which is too long. For the space inside the high-bay warehouse, this even takes over $130 \mathrm{~h}\left(60{ }^{\circ} \mathrm{C}\right.$ coil temperature), or more than $160 \mathrm{~h}$ for the coil to reach $50^{\circ} \mathrm{C}$. To wait this long for the cooling down would require a very large and therefore inefficient and expensive buffer storage.

The overall results indicate that by using the verified and updated thermal model and the calculations of this study, the application of a ventilation system with outdoor air can lead to the desired outcome and benefits.

The data obtained in this study shows that a system that makes economic and ecological sense can be installed in a high-bay warehouse using comparatively simple means. The system consists mainly of fans, air ducts and exhaust grids.

The airflow simulation and the measurements also show that even with the added safety of $20 \%$ and twice the calculated volume of supply air the simulated cooling process was matched. In contrast to a closed system, in the open environment of the warehouse the airflow directed to the test objects could not completely reach the surface of the metal cylinders. Despite the higher air volume compared to the calculation, the application reduces the power consumption by the factor of 16 . In addition to the savings in energy and logistics, and therefore money, there is the benefit of reducing the carbon dioxide output. With an electricity mix of around 550 grams of $\mathrm{CO}_{2}$ per $\mathrm{kWh}$, this means a saving of $136 \mathrm{~kg} \mathrm{CO}_{2}$ per aluminium coil. The benchmark for a $20 \mathrm{t}$ aluminium cylinder would 
be $6.8 \mathrm{~kg} \mathrm{CO}_{2}$ savings per metric ton. Worldwide this system could eliminate about $476,000 \mathrm{t}$ of $\mathrm{CO}_{2}$ output per year. This is only a small portion of the total $\mathrm{CO}_{2}$ output of the aluminium production but still it is a portion and it makes ecological and economic sense to install the cooling system.

The limitations of this study are clear: there were only a small number of test objects available. It is hard to come by $20 \mathrm{t}$ test objects just for experimental purposes and be able to access them in the surrounding of a fully automated storage facility. Another point is that the test coils did not reach the maximum dimensions that were stated in the initial requirements. In addition, the influence of fluctuations in outdoor temperature was neglected by using an average value. It was justifiable in this study because the maxima still provided enough difference for a working heat flow.

This study provides a new application for reducing the energy consumption and eliminating an additional logistic step in aluminium production and saving money with an economically feasible system. It therefore also reduces the output of carbon dioxide and as a result the ecological footprint. Further research could optimize the ventilation system and make the airflow even more efficient. With a worldwide production of about 70 million metric tons per year, this should be achievable.

\section{Acknowledgement}

The authors thank the Federal Ministry of Education and Research of the Federal Republic of Germany for realizing this project within the framework of the ZIM funding program.. The authors also acknowledge the support of Vollert GmbH in Germany for experimental support. The authors thank the support of the engineering team of $S+P$ Ingenieure AG, Heilbronn, Germany, during the conduction of the measurements.

\section{References}

[1] G. Liu, D.B. Müller, J. Clean. Prod. 35 (2012) 108-117.

[2] M. Bagheripoor, H. Bisadi, Appl. Therm. Eng. 31 (2011) 1556-1565.

[3] P. Hao, A. He, W. Sun, Arch. Civ. Mech. Eng. 18 (2018) 245-255.

[4] A.R. Riahi, O.A. Gali, K.R. Januszkiewicz, D. Pattemore, Tribol. Int. 54 (2012) 42-50.

[5] H. Changqing, D. Hua, C. Jie, H.. Xinghua, Y. Shuangcheng, Procedia Eng. 16 (2011) 745-754.

[6] A. Javaid, F. Czerwinski, J. Magnes. Alloy. 7 (2019) 27-37.

[7] Z.-Y. Hu, Z.-H. Zhang, X.-W. Cheng, Q. Song, S. Yin, H. Wang, F.-C. Wang, Mater. Sci. Eng. A 737 (2018) 90-93.
[8] G. Falkinger, P. Simon, Procedia Eng. 207 (2017) 31-36.

[9] Y. Hu, Y. He, H. Gao, Z. Zhang, Appl. Therm. Eng. 155 (2019) 650-659.

[10] T.K. Ibrahim, A.T. Al-Sammarraie, W.H. AlTaha, M. Reza Salimpour, M. Al-Jethelah, A.N. Abdalla, H. Tao, Appl. Therm. Eng. (2019) 113974.

[11] B. Kwon, L. Liebenberg, A.M. Jacobi, W.P. King, Int. J. Heat Mass Transf. 137 (2019) 292-300.

[12] K. Bilen, S. Gok, A.B. Olcay, I. Solmus, Energy 138 (2017) 1187-1198.

[13] T. Naemsai, N. Kammuang-lue, P. Terdtoon, P. Sakulchangsatjatai, Appl. Therm. Eng. 148 (2019) 886-896.

[14] C. Byon, Int. J. Heat Mass Transf. 84 (2015) 1056-1060.

[15] G. Chen, Y. Tang, Z. Wan, G. Zhong, H. Tang, J. Zeng, Int. Commun. Heat Mass Transf. 100 (2019) $12-19$.

[16] K. Zhao, D. Ren, B. Wang, Y. Chang, Int. J. Heat Mass Transf. 132 (2019) 293-300.

[17] C. Wantha, Appl. Therm. Eng. 157 (2019) 113747.

[18] W.-H. Shih, C.-C. Liu, W.-H. Hsieh, Int. J. Heat Mass Transf. 97 (2016) 742-750.

[19] J.H.L. Iv, J.H. Lienhard, J. Heat Transfer 108 (1986) 198.

[20] A. Atreya, in: SFPE Handb. Fire Prot. Eng. Fifth Ed., 2016, pp. 53-101.

[21] F. Kreith, M. Bohn, A. Kirkpatrick, J. Sol. Energy Eng. 119 (1997) 187.

[22] K. Bordo, V.C. Gudla, L. Peguet, A. Afseth, R. Ambat, Corros. Sci. 131 (2018) 28-37.

[23] M.D. Ernst Doering, Herbert Schedwill, Grundlagen Der Technischen Thermodynamik Lehrbuch Für Studierende Der Ingenieurwissenschaften, 2012.

[24] H.D. Baehr, K. Stephan, Wärme- Und Stoffübertragung ('Heat and Mass Transfer'), Springer Berlin Heidelberg, Berlin, Heidelberg, 2008.

[25] H. Martin, VDI-Wärmeatlas, 10.Auflage, Springer Berlin Heidelberg New York, Berlin Heidelberg, 2006. 